\title{
PReS-FINAL-2260: Provisional findings of an on-going study of musculoskeletal anomalies in a national cohort of patients with trisomy 21
}

\author{
C Foley $^{1 *}$, OG Killeen ${ }^{2}$ \\ From 20th Pediatric Rheumatology European Society (PReS) Congress \\ Ljubljana, Slovenia. 25-29 September 2013
}

\begin{abstract}
Introduction
Musculoskeletal complications of Down syndrome are common. Joint laxity is almost universal. This, in combination with low muscle tone, contribute to increased risk of a number of musculoskeletal disorders e.g. atlanto-axial instability, patella instability \& pes planus. Arthritis in children with Down syndrome is also reported. Down's Arthropathy (DA) is thought to be 3-6 times more common than JIA in the general paediatric population. Despite this fact, DA is rarely recognised at onset \& remains under-diagnosed. This contributes to unnecessary disability \& functional impairment.
\end{abstract}

\section{Objectives}

1.Take a musculoskeletal history from, and perform a musculoskeletal examination on children with Down syndrome between the ages of 0.5-18 years. 2.Score hypermobility using the Beighton \& Brighton screening tools. 3.Examine joints for evidence of past and/or present arthritis.

\section{Methods}

From April 2013 to April 2014, children with Down syndrome will be invited to attend a screening clinic.
Screening involves completion of a health questionnaire \& a comprehensive musculoskeletal exam.

\section{Results}

Our results support a feature consistently reported in the limited literature available on DA (table 1). There is delayed diagnosis, leading to less favourable outcomes. The average time to diagnosis in our cohort was 1.9 years, with the longest delay reported nearly 5 years. This child developed loss of joint space, generalized osteopenia, erosions \& subluxations of affected joints. When compared with a cohort of our newly diagnosed JIA patients (time to diagnosis 0.6 years), we demonstrate a significant difference in time to diagnosis $(\mathrm{p}=0.025)$. To date 59 children have enrolled in the musculoskeletal screening process, $69 \%$ of whom have pes planus. No atlanto-axial instability has been reported, however one child had an absent $\mathrm{C} 2$ vertebra. There has been one case of patella instability and 4 new cases of DA diagnosed. Anecdotally we have not found the Beighton \& Brighton criteria comprehensive. The majority of children were found to have hypermobile hips. Neither scoring systems incorporate hips in their screening criteria.

Table 1

\begin{tabular}{llllll}
\hline & & Average & Std. Dev. & Minimum & Maximum \\
\hline $\begin{array}{c}\text { Current Down's Arthropathy Cohort } \\
n=12\end{array}$ & Age (years) & 8.5 & 4.5 & 0.3 & 14.9 \\
& & & & \\
& Active Joint Count* & 6 & 3.7 & 1 & 11 \\
& Restricted Joint Count* & 3 & 3.3 & 0 & 12 \\
& Delay in Diagnosis (years) & 1.9 & 1.5 & 0.2 & 4.9 \\
& & & & & $*$ At Presentation
\end{tabular}

${ }^{1} \mathrm{OLCHC/NCRC,}$ Dublin, Ireland

Full list of author information is available at the end of the article 
To date $100 \%$ of children screened would not have BHS using Brighton criteria.

\section{Conclusion}

Pes planus is commonly seen in children with T21, therefore orthotics \& advice regarding correct footwear is important. Children with T21 often have hypermobile hips, not accounted for by the current scoring criteria for BHS. DA is common but often missed, with delayed diagnosis. Early diagnosis \& treatment of DA is important to prevent unwanted joint destruction \& functional disability. Children with T21 should have a musculoskeletal exam as part of their annual screening programme.

\section{Disclosure of interest}

None declared.

\section{Authors' details}

'OLCHC/NCRC, Dublin, Ireland. ${ }^{2} \mathrm{OLCHC}$, Dublin, Ireland.

Published: 5 December 2013

doi:10.1186/1546-0096-11-S2-P250

Cite this article as: Foley and Killeen: PReS-FINAL-2260: Provisional

findings of an on-going study of musculoskeletal anomalies

in a national cohort of patients with trisomy 21. Pediatric Rheumatology

2013 11(Suppl 2):P250

Submit your next manuscript to BioMed Central and take full advantage of:

- Convenient online submission

- Thorough peer review

- No space constraints or color figure charges

- Immediate publication on acceptance

- Inclusion in PubMed, CAS, Scopus and Google Scholar

- Research which is freely available for redistribution

Submit your manuscript at www.biomedcentral.com/submit 